\title{
The susceptibility of antibiotics for intracanal bacteria removal using E. faecalis biofilm model
}

\author{
Su-Hee Go ${ }^{1}$, So-Hee Kim², In-Chol Kang ${ }^{2}$, In-Nam Hwang ${ }^{1}$, Won-Mann $\mathrm{Oh}^{1}$, and Yun-Chan Hwang ${ }^{1 *}$ \\ ${ }^{1}$ Department of Conservative Dentistry, School of Dentistry, Dental Science Research Institute, Chonnam National Uni- \\ versity, Gwangju 61186, Republic of Korea \\ ${ }^{2}$ Department of Oral Microbiology, School of Dentistry, Dental Science Research Institute, Chonnam National Univer- \\ sity, Gwangju 61186, Republic of Korea
}

(Received Jun 2, 2017; Revised version received Jul 5, 2017; Accepted Jul 7, 2017)

\begin{abstract}
Most root canal procedures are anatomically complex, resulting in insufficient removal of the necrotic pulp by mechanical root canal shaping. This study evaluated the use of antibiotics as canal irrigants for removal of susceptible intracanal bacteria, using an Enterococcus faecalis biofilm model. Enterococcus faecalis biofilm was developed in the root canal and test tube. For the experiments, sodium hypochlorite $(\mathrm{NaOCl})$, augmentin and erythromycin were used as intracanal irrigants. The test tubes and canals were prepared and irrigated with phosphate buffered saline (PBS), $\mathrm{NaOCl}$, augmentin and erythromycin. Bacterial samples were collected after irrigation in the test tube models on day 1 , and from the tooth model on days 1, 4 and 7 . The surface of each sample and attached pattern of the bacteria was also analyzed by examining under scanning electron microscopy (SEM). The antibacterial study using $10 \mathrm{ml}$ test tubes ( $\mathrm{n}=10$ ) revealed that $5 \% \mathrm{NaOCl}$, augmentin and erythromycin inhibited bacterial growth relative to PBS. In the tooth model, $\mathrm{NaOCl}$, augmentin and erythromycin inhibited bacterial growth significantly (all $\mathrm{p}<0.05$ ) at days 4 and 7 , relative to PBS. Compared to day 1 , bacterial density of all groups reduced at day 7, and changes in cell morphology were observed in all experimental groups. Our studies revealed evidence of significant differences in the antimicrobial efficacy at days 4 and 7, upon irrigation with augmentin and erythromycin versus PBS, in root canals infected with E. faecalis.
\end{abstract}

KEY WORDS: Augmentin, Biofilm, Canal irrigation, Enterococcus faecalis, Erythromycin

\section{Introduction}

The main purpose of root canal therapy is to remove dental pulp, remaining dentin and microorganisms from the root canal system. Most of the root canal is anatomically complex, which leads to an insufficiency in removing the entire necrotic pulp by mechanical root canal shaping. Thus, it is necessary to use intracanal irrigants in the middle of a mechanical root canal shaping procedure. Currently, sodium hypochlorite $(\mathrm{NaOCl})$ is the most popular irrigant in root canal therapy. $\mathrm{NaOCl}$ effectively

*Corresponding author: Yun-Chan Hwang

Department of Conservative Dentistry, School of Dentistry, Chonnam National University. Young-bong ro 77, Bukgu, Gwangju 61186, Republic of Korea

Tel.: +82-62-530-5831, Fax: +82-62-530-5629

E-mail: ychwang@chonnam.ac.kr removes organic tissue and virus. $\mathrm{NaOCl}$ has strong antimicrobial activity. Its use combined with instrumentation removes the majority of the microbial cells in the root canal. However, a small portion of the flora survives [1].

Enterococcus faecalis is a facultative anaerobic grampositive coccus and is the most common Enterococcus species cultured from non-healing endodontic cases. It persists in treated root canals [2-5]. E. faecalis has been suggested as the main cause for endodontic failure. With its resistance to intracanal medicaments and even to $\mathrm{pH}$ 11.5 environments, E. faecalis is able to tolerate calcium hydroxide antimicrobial treatment [6]. As it can also tolerate persistent nutrient starvation, E. faecalis can survive more than 4 weeks after canal filling, and proliferates as a single infection type without the presence of other bacteria.

Various methods for the elimination of E. faecalis have been studied. These include the use of various instru- 
ments, intracanal irrigant regimens, intracanal medicaments, and local application of antibiotics within the root canal system. E. faecalis is resistant to multiple antimicrobial agents, so the selection and use of the appropriate local antibiotics to the persistent endodontic infections is challenging [7].

Resistance of $E$. faecalis is caused by formation of a biofilm that harbors multiple bacteria in an intracanal polysaccharide matrix [8]. The biofilm mode of growth confers antibiotic resistance $[9,10]$ and can protect the bacteria from defense mechanisms of the immune system. When E. faecalis grows as a biofilm, the genetic and metabolic transformations in the adherent bacteria prevent the penetration and action of several antimicrobial agents [11]. E. faecalis that invades the dentinal tubules may survive in chemomechanical instrumentation and intracanal medication [12], and can colonize tubules and reinfect the obturated root canals [13].

Augmentin contains a combination of amoxicillin and clavulanate potassium. Amoxicillin is a penicillin antibiotic. Clavulanate potassium is a form of clavulanic acid similar to penicillin. Augmentin is used to treat many different infections caused by bacteria, such as sinusitis, pneumonia, ear infections, bronchitis, urinary tract infections, and infections of the skin. Erythromycin is a that has an antimicrobial spectrum similar to or slightly wider than that of penicillin, and is often for people who have an to penicillin antibiotics.

To increase antibiotic activity to the experimentally formed E. faecalis biofilm, antibiotics were used as intracanal irrigants, which in solution could reach to the inaccessible dentinal tubule. The purpose of this study was to evaluate the susceptibility of antibiotics as canal irrigants for removal of intracanal bacteria using an E. faecalis biofilm model.

\section{Materials and Methods}

\section{Sample preparation}

Single-rooted human teeth with fully formed apices were used. All teeth were stored in $0.5 \%$ thymol solution at $4^{\circ} \mathrm{C}$ before use. The crowns were removed and the tooth length was standardized to $17 \mathrm{~mm}$ from the root apex to the coronal border. Samples were flared using a \#4 GatesGlidden bur in the coronal third, and then instrumented using the crown-down technique and rotary instruments
(BLX Ni-Ti file; B\&L Biotech, Seoul, Korea). Following preparation, each tooth was irrigated with $5 \mathrm{ml}$ of $5 \%$ $\mathrm{NaOCl}$, followed by $5 \mathrm{ml}$ of saline to remove the smear layer. Samples were dried with a paper point, fixed to an Eppendorf tube by an orthodontic acrylic resin (Ortho-Jet, Lang Dental Manufacturing, Wheeling, IL), and sterilized for 15 minutes at $121^{\circ} \mathrm{C}$.

\section{Biofilm formation and application of the antimicrobial agents}

E. faecalis (NCTC 29211) cultures were grown overnight in Tryptone Soy Broth (TSB) at $37^{\circ} \mathrm{C}$. The supernatant was centrifuged, dissolved in fresh TSB $\left(5 \times 10^{7}\right.$ colony forming units $(\mathrm{CFU}) / \mathrm{ml})$ and cultured in $10 \mathrm{ml}$ test tubes for 1 week to prepare tooth sample and test tube. Samples were cultured in an anaerobic chamber at $37^{\circ} \mathrm{C}$ in an environment of $85 \% \mathrm{~N}_{2}, 10 \% \mathrm{H}_{2}$, and $5 \% \mathrm{CO}_{2}$.

After the biofilm-formed root canal was washed twice using phosphate buffered saline (PBS), it was treated with PBS, $5 \% \mathrm{NaOCl}$, augmentin, and erythromycin for 1, 4, and 7 days. For the test tube group, all intracanal irrigants treated for 1 day only. The concentration of the antibiotics was as previously described [14]. At each step, the root canal was washed twice by PBS, and the bacteria were removed by sterilized paper point and dissolved in PBS. Absorbance of the dissolved bacteria was measured at 600 nm using a spectrophotometer. E. faecalis CFU was measured at intervals during the 48-hour growth on TSB agar.

\section{Scanning electron microscopy (SEM)}

Bacterial biofilm development onto root canal dentin was monitored by SEM examination at 1, 4, and 7 days. Each group treated with intracanal irrigant was immersed in $2 \%$ glutaraldehyde and $2 \%$ paraformaldehyde buffering with $0.05 \mathrm{M}$ cacodylate buffer ( $\mathrm{pH} 7.2$ ) for 4 hours at $4^{\circ} \mathrm{C}$ for fixation, washed three times with $0.05 \mathrm{M}$ cacodylate buffer ( $\mathrm{pH}$ 7.2) and then dehydrated in an ascending ethanol series $(50 \%, 70 \%, 90 \%, 95 \%$, and $100 \%)$ for $10 \mathrm{~min}$ utes each. The samples were treated with t-butylalcohol for 2 hours at $-20^{\circ} \mathrm{C}$ and then frozen using liquid nitrogen. The samples were split using a hammer and chisel. Finally, the samples were dried using a freezing dryer apparatus (LABCONCO, Kansas City, MO) using liquid $\mathrm{CO}_{2}$ replacement. Each sample was mounted and coated with a $200 \AA$ layer of gold palladium. The canal was observed by using a S-4700 field-emission scanning electron microscope (Hitachi, Tokyo, Japan) at $30 \mathrm{kV}$ at days 


\section{1,4 , and 7.}

\section{Statistical analysis}

One-way ANOVA was performed to elucidate the effect of each antibiotic. SPSS 18.0 (SPSS, Chicago, IL) was used. Elapsed time and type of antibiotics were assigned as fixed factors, CFU enumeration was assigned as a dependent variable. Additional post-hoc analysis was performed to confirm difference of each group. Significance level was 0.05 .

\section{Results}

Antibacterial study using $10 \mathrm{ml}$ test tube $(\mathrm{n}=10)$ revealed that the $5 \% \mathrm{NaOCl}$, augmentin, and erythromycin inhibited bacterial growth relative to PBS (Fig. 1). CFU determinations and SEM analysis of the tooth model $(n=9)$ revealed that $\mathrm{NaOCl}$, augmentin, and erythromycin inhibited bacterial growth significantly $(p<.05)$ at day 4 and 7 relative to bacteria cultured without intracanal irrigants and to PBS (Table 1). Fig. 2 displays a representative

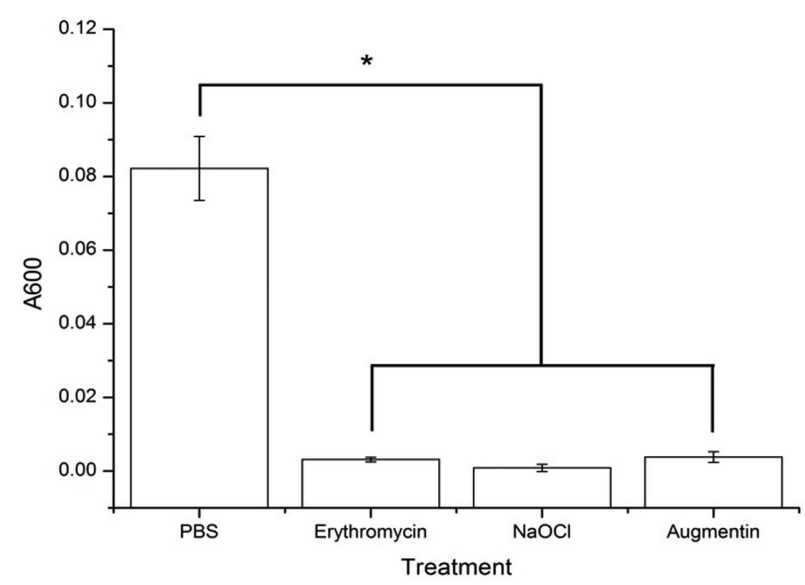

Fig. 1. Absorbance at $600 \mathrm{~nm}$ after 1 day of treatment with each intracanal irrigant using $10 \mathrm{ml}$ polypropylene test tubes. All irrigants significantly reduced biofilm compared with PBS.
SEM image of bacteria at day 1 and 7. Compared to day 1 , bacterial density of all groups reduced at day 7 and morphology was changed in all experimental groups.

\section{Discussion}

Persistent endodontic disease after root canal therapy may be caused by bacteria in dentinal tubules [15]. Current mechanical techniques of root canal treatment may leave untreated areas of the root canal system [16]. Mechanical instrumentation without irrigation is insufficient to eliminate bacteria in the canal [17-19]. Therefore, intracanal irrigant is necessary for efficient removal of bacteria.

In this study, the two antibiotics selected have been reported as efficient agents for E. faecalis [4,5,20,21]. CFU determinations and SEM analysis revealed that $\mathrm{NaOCl}$, augmentin, and erythromycin inhibited bacterial growth significantly $(p<.05)$ at day 4 and 7 relative to control and PBS. In the case of erythromycin, we used erythromycin standard solution (Sigma-Aldrich, St Louis, MO) in the pilot study. By using this solution, we expected this intracanal irrigant to work more efficiently against $E$. faecalis biofilm. However, because the limited solubility that prevented reaching the appropriate concentration, we finally used a powdered form of erythromycin dissolved in ethanol and then filtered. It was possible that the ethanol solvent might have synergistically increased the killing effect of erythromycin on E. faecalis.

The primary goal of this study was to evaluate the possibility of using antibiotics as an intracanal irrigant, rather than an intracanal medicament. The ideal intracanal irrigant has rapid antibacterial activity, dissolves necrotic tissue, lubricates the canal, removes the smear layer, and does not irritate healthy tissues $[22,23]$. Therefore, we first performed test tube experiments to define the appropriate application time for eliminating E. faecalis biofilm. $\mathrm{NaOCl}$,

Table 1. Quantitative analysis of E. faecalis biofilm formed on root canals for different groups at days 1, 4, and $7(p<.05)$

\begin{tabular}{|c|c|c|c|c|c|c|}
\hline & \multicolumn{2}{|c|}{1 day } & \multicolumn{2}{|c|}{4 day } & \multicolumn{2}{|c|}{7 day } \\
\hline & Mean CFU & SD & Mean CFU & SD & Mean CFU & SD \\
\hline PBS & $28.1 \times 10^{5 \mathrm{a}}$ & $3.5 \times 10^{5}$ & $26.8 \times 10^{5 \mathrm{a}}$ & $4.2 \times 10^{5}$ & $33.4 \times 10^{5 \mathrm{a}}$ & $3.3 \times 10^{5}$ \\
\hline $\mathrm{NaOCl}$ & $28.4 \times 10^{5 \mathrm{a}}$ & $3.8 \times 10^{5}$ & $0.8 \times 10^{5 \mathrm{c}}$ & $0.4 \times 10^{5}$ & $0.2 \times 10^{5 b}$ & $0.2 \times 10^{5}$ \\
\hline Erythromycin & $28.7 \times 10^{5 \mathrm{a}}$ & $6.7 \times 10^{5}$ & $23.1 \times 10^{5 \mathrm{ab}}$ & $3.2 \times 10^{5}$ & $4.3 \times 10^{5 \mathrm{c}}$ & $0.5 \times 10^{5}$ \\
\hline Augmentin & $29.7 \times 10^{5 \mathrm{a}}$ & $3.3 \times 10^{5}$ & $16.7 \times 10^{5 b}$ & $7.4 \times 10^{5}$ & $12.2 \times 10^{5 \mathrm{~d}}$ & $1.7 \times 10^{5}$ \\
\hline
\end{tabular}

PBS: phosphate buffered saline; Different letter means significant difference. 
A
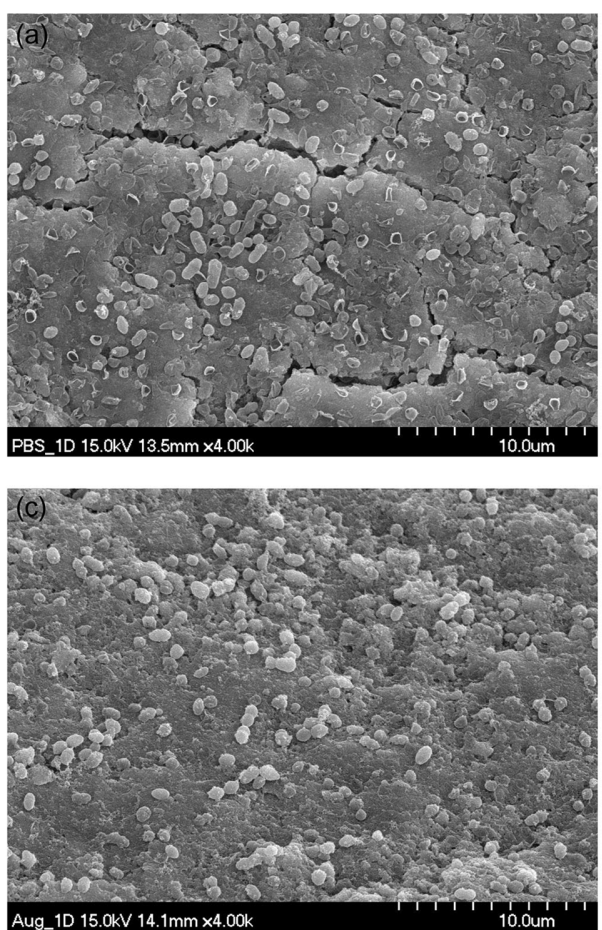

B
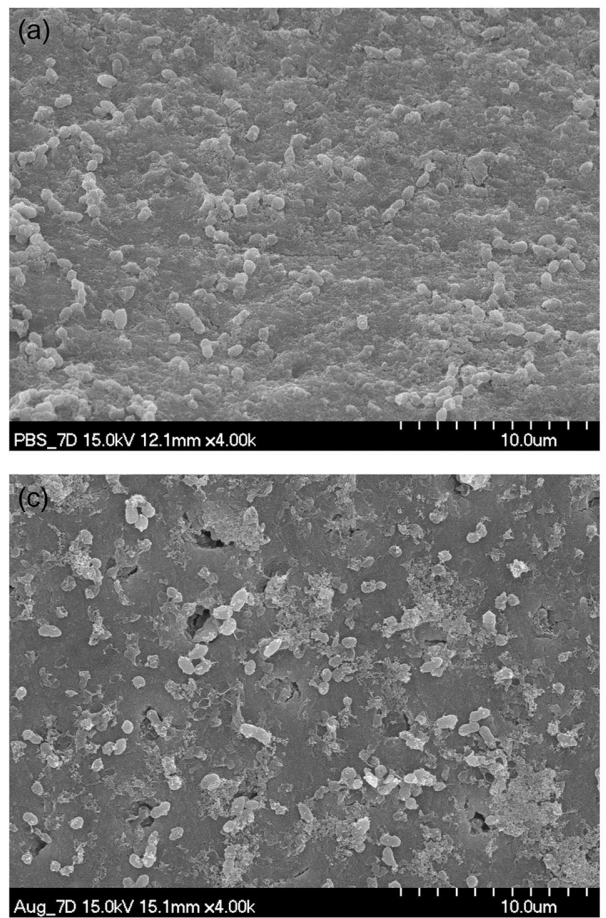
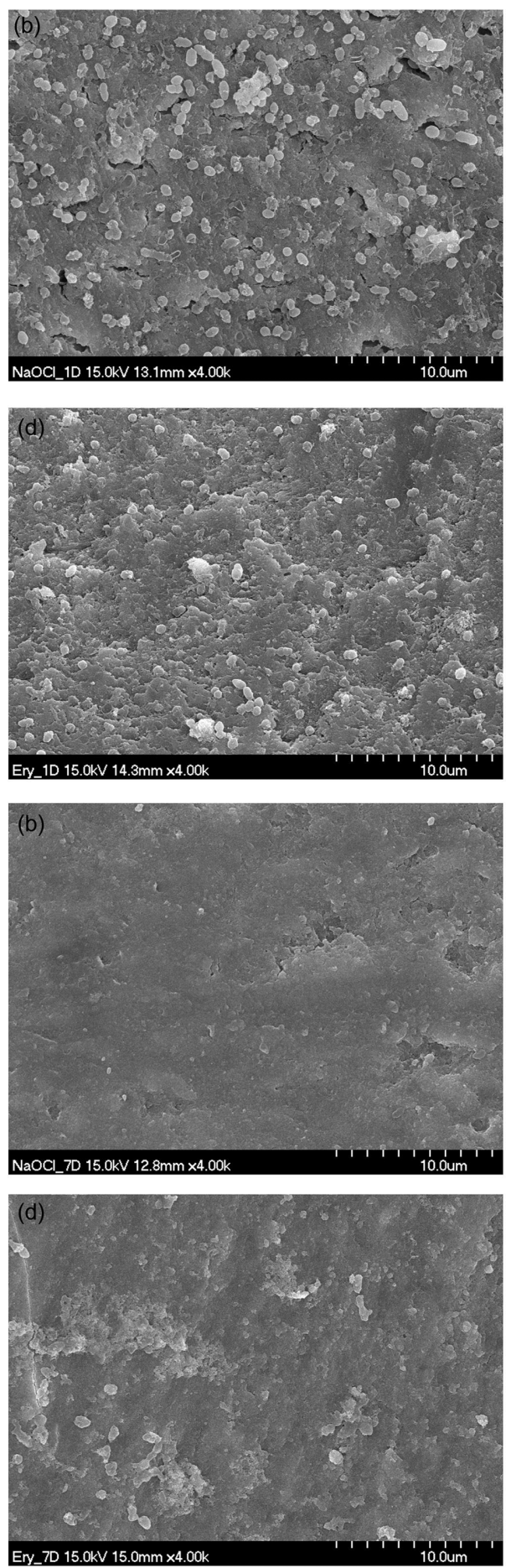

Fig. 2. Scanning electron microscopy image of bacteria in the tooth model. A. Images acquired at one day. (a) PBS group (top left: 4,000X), (b) $\mathrm{NaOCl}$ group (top right: 4,000X), (c) Augmentin group (bottom left: 4,000X), and (d) Erythromycin group (bottom right: 4,000X). B. Images acquired at 7 days. (a) PBS group (top left: 4,000X), (b) $\mathrm{NaOCl}$ group (top right: 4,000X), (c) Augmentin group (bottom left: 4,000X), and (d) Erythromycin group (bottom right: 4,000X).

erythromycin, and augmentin displayed significantly lower absorbance compared to PBS at day 1 (Fig. 1). However, in the tooth model, there were no significant differences among the experimental groups on day 1 . The reason might be the complexity of root canal, which is different from the test tube.

$\mathrm{NaOCl}$, erythromycin, and augmentin significantly reduced intracanal bacteria levels compared with the use of PBS 
on day 4 and 7. Augmentin showed lower intracanal bacteria levels compared with erythromycin on day 4. However, there was no statistical difference between augmentin and erythromycin. In contrast, the intracanal bacterial level of erythromycin was significantly lower than that of augmentin on day $7(p<.05)$. The bacterial density of erythromycin was lower than that of augmentin (Fig. 2). As mentioned earlier, the solvent may have had a synergistic effect on elimination of E. faecalis.

In conclusion, the results of this study showed significant differences in the antimicrobial efficacy of irrigating with $1 \% \mathrm{NaOCl}$ irrigant was most effective method to remove E. faecalis. Also, significant differences were apparent in the antimicrobial efficacy of irrigation with augmentin and erythromycin versus PBS in the root canal infected with E. faecalis on day 4 and 7.

\section{Acknowledgements}

The authors have no conflicts of interest related to this study.

\section{Conflict of Interest}

The authors declare that they have no competing interests.

\section{ORCID}

$\begin{array}{ll}\text { Su-Hee Go } & 0000-0003-1175-3094 \\ \text { So-Hee Kim } & 0000-0001-5038-4215 \\ \text { In-Chol Kang } & 0000-0002-5993-8728 \\ \text { In-Nam Hwang } & 0000-0002-5388-1919 \\ \text { Won-Mann Oh } & 0000-0001-6480-6191 \\ \text { Yun-Chan Hwang } & 0000-0002-7891-9565\end{array}$

\section{References}

1. Prabhakar J, Senthilkumar M, Priya M, Mahalakshmi K, Sehgal P, Sukumaran V. Evaluation of antimicrobial efficacy of herbal alternatives (Triphala and green tea polyphenols), MTAD, and 5\% sodium hypochlorite against Enterococcus faecalis biofilm formed on tooth substrate: an in vitro study. J Endod 2010;36:83-86. doi: 10.1016/ j.joen.2009.09.040.

2. Peters L, Wesselink P, Buijs J, Van Winkelhoff A. Viable bacteria in root dentinal tubules of teeth with apical periodontitis. J Endod 2001;27:76-81. doi: 10.1097/00004770200102000-00002.

3. Dahlén G, Samuelsson W, Molander A, Reit C. Identification and antimicrobial susceptibility of enterococci isolated from the root canal. Oral Microbiol Immunol 2000;15:309-312. doi: 10.1034/j.1399-302x.2000.150507.x.

4. Pinheiro E, Gomes B, Ferraz C, Teixeira F, Zaia A, Souza Filho F. Evaluation of root canal microorganisms isolated from teeth with endodontic failure and their antimicrobial susceptibility. Oral Microbiol Immunol 2003;18: 100103. doi: 10.1034/j.1399-302X.2003.00058.x.

5. Skucaite N, Peciuliene V, Vitkauskiene A, Machiulskiene V. Susceptibility of endodontic pathogens to antibiotics in patients with symptomatic apical periodontitis. J Endod 2010;36:1611-1616. doi: 10.1016/j.joen.2010.04.009.

6. Sundqvist G, Figdor D, Persson S, Sjögren U. Microbiologic analysis of teeth with failed endodontic treatment and the outcome of conservative re-treatment. Oral Surg Oral Med Oral Pathol Oral Radiol Endod 1998;85:86-93. doi: 10.1016/S1079-2104(98)90404-8.

7. Marothi Y, Agnihotri H, Dubey D. Enterococcal resistance-an overview. Indian J Med Microbiol 2005;23:214.

8. Distel JW, Hatton JF, Gillespie MJ. Biofilm formation in medicated root canals. J Endod 2002;28:689-693. doi: 10.1097/00004770-200210000-00003.

9. Kouidhi B, Zmantar T, Mahdouani K, Hentati H, Bakhrouf A. Antibiotic resistance and adhesion properties of oral Enterococci associated to dental caries. BMC Microbiol 2011;11:155. doi: 10.1186/1471-2180-11-155.

10. Sun J, Sundsfjord A, Song X. Enterococcus faecalis from patients with chronic periodontitis: virulence and antimicrobial resistance traits and determinants. Eur J Clin Microbiol Infect Dis 2012;31:267-272. doi: 10.1007/ s10096-011-1305-z.

11. Gordon C, Hodges N, Marriott C. Antibiotic interaction and diffusion through alginate and exopolysaccharide of cystic fibrosis-derived Pseudomonas aeruginosa. J Antimicrob Chemother 1988;22:667-674.

12. Orstavik D, Haapasalo M. Disinfection by endodontic irrigants and dressings of experimentally infected dentinal tubules. Dent Traumatol 1990;6:142-149.

13. Love R. Enterococcus faecalis-a mechanism for its role in endodontic failure. Int Endod J 2001;34:399-405. doi: 10.1046/j.1365-2591.2001.00437.x.

14. Andrews JM. Determination of minimum inhibitory concentrations. J Antimicrob Chemother 2001;48:5-16.

15. Safavi KE, Spngberg LS, Langeland K. Root canal dentinal tubule disinfection. J Endod 1990;16:207-210.

16. Davis SR, Brayton SM, Goldman M. The morphology of the prepared root canal: a study utilizing injectable sili- 
cone. Oral Surg Oral Med Oral Pathol 1972;34:642-648.

17. Byström A, Sundqvist G. Bacteriologic evaluation of the efficacy of mechanical root canal instrumentation in endodontic therapy. Eur J Oral Sci 1981;89:321-328.

18. Yamada RS, Armas A, Goldman M, Lin PS. A scanning electron microscopic comparison of a high volume final flush with several irrigating solutions: Part 3. J Endod 1983;9:137-142. doi: 10.1016/S0099-2399(83)80032-6.

19. Baumgartner JC, Mader CL. A scanning electron microscopic evaluation of four root canal irrigation regimens. J Endod 1987;13:147-157.

20. Pinheiro E, Gomes B, Drucker D, Zaia A, Ferraz C, Souza-Filho F. Antimicrobial susceptibility of Enterococcus faecalis isolated from canals of root filled teeth with periapical lesions. Int Endod J 2004;37:756-763. doi: 10.1111/j.1365-2591.2004.00865.x.

21. Hoelscher AA, Bahcall JK, Maki JS. In vitro evaluation of the antimicrobial effects of a root canal sealer-antibiotic combination against Enterococcus faecalis. J Endod 2006;32:145-147. doi: 10.1016/j.joen.2005.10.031.

22. Goldman LB, Goldman M, Kronman JH, Lin PS. The efficacy of several irrigating solutions for endodontics: a scanning electron microscopic study. Oral Surg Oral Med Oral Pathol 1981;52:197-204.

23. Hülsmann M, Heckendorff M, Lennon A. Chelating agents in root canal treatment: mode of action and indications for their use. Int Endod J 2003;36:810-830. doi: 10.1111/j.1365-2591.2003.00754.x. 